\title{
Apoptotic SKOV3 cells stimulate M0 macrophages to differentiate into M2 macrophages and promote the proliferation and migration of ovarian cancer cells by activating the ERK signaling pathway
}

\author{
QUN ZHANG ${ }^{1}$, HUI LI $^{1}$, YIQING MAO ${ }^{1}$, XI WANG $^{1}$, XUEHUI ZHANG $^{1}$, XIUYAN YU $^{1}$, \\ JUNRUI TIAN ${ }^{1}$, ZHEN LEI ${ }^{2}$, CHANG LI ${ }^{1}$, QING HAN ${ }^{1}$, LIPING SUO ${ }^{1}$, YAN GAO ${ }^{3}$, \\ HONGYAN GUO ${ }^{3}$, DAVID M. IRWIN ${ }^{4}$, GANG NIU $^{2}$ and HUANRAN TAN ${ }^{1}$
}

\begin{abstract}
${ }^{1}$ Department of Pharmacology, School of Basic Medical Sciences, Peking University Health Science Center, Beijing 100191; ${ }^{2}$ Beijing N\&N Genetech Company, Beijing 100082; ${ }^{3}$ Department of Obstetrics and Gynecology, Peking University Third Hospital, Beijing 100191, P.R. China; ${ }^{4}$ Department of Laboratory Medicine and Pathobiology, University of Toronto, Toronto, ON M5S 1A8, Canada
\end{abstract}

Received March 31, 2019; Accepted August 27, 2019

DOI: $10.3892 / \mathrm{ijmm} .2019 .4408$

\begin{abstract}
Ovarian cancer has a high rate of recurrence, with M2 macrophages having been found to be involved in its progression and metastasis. To examine the relationship between macrophages and ovarian cancer in the present study, M0 macrophages were stimulated with apoptotic SKOV3 cells and it was found that these macrophages promoted tumor proliferation and migration. Subsequently, the mRNAs and proteins expressed at high levels in these M2 macrophages were examined by RNA-Seq and quantitative proteomics, respectively, which revealed that M0 macrophages stimulated by apoptotic SKOV3 cells also expressed M2 markers, including CD206, interleukin-10, C-C motif chemokine ligand 22, aminopeptidase-N, disabled homolog 2, matrix metalloproteinase 1 and 5'-nucleotidase. The abundance of phosphorylated Erk1/2 in these macrophages was increased. The results indicate that apoptotic SKOV3 cells stimulate M0 macrophages to differentiate into M2 macrophages by activating the ERK pathway. These results suggest possible treatments for patients with ovarian cancer who undergo chemotherapy; inhibiting M2 macrophage differentiation during chemotherapy may reduce the rate of tumor recurrence.
\end{abstract}

Correspondence to: Professor Huanran Tan, Department of Pharmacology, School of Basic Medical Sciences, Peking University Health Science Center, 38 Xueyuan Road, Beijing 100191, P.R. China E-mail: tanlab@bjmu.edu.cn

Dr Hongyan Guo, Department of Obstetrics and Gynecology, Peking University Third Hospital, 49 Huayuan North Road, Haidian, Beijing 100191, P.R. China

E-mail: bysyghy@163.com

Key words: apoptotic SKOV3, M2 macrophage, quantitative proteomics, RNA-Seq, ERK pathway

\section{Introduction}

Ovarian cancer is the leading cause of mortality in patients with gynecologic malignancies. In 2017, 22,440 women were diagnosed with ovarian cancer in the United States, with 14,080 deaths (1). The mortality and recurrence rates of advanced disease in ovarian cancer are high (2). Standard therapy for ovarian cancer involves surgery followed by chemotherapy. The most common chemotherapeutic treatment for ovarian cancer is cisplatin (DDP) combined with taxane treatment (3). Although standard treatment can effectively remove tumors, $70-80 \%$ of patients with advanced disease relapse within a few months to years and acquire tumors exhibiting DDP resistance $(3,4)$. Recurrence is a major challenge in the treatment of ovarian cancer.

The occurrence and metastasis of tumors are closely associated with the tumor microenvironment (5). Tumor microenvironments are mainly composed of extracellular matrix, fibroblasts, vascular endothelial cells and immune cells (6). Tumor-associated macrophages (TAMs) are important in tumor occurrence and metastasis. Monocytes differentiate into two distinct types of macrophages, classically activated, or M1, macrophages and alternatively activated, or M2, macrophages. The majority of TAMs have the M2 phenotype (7). M1 macrophages typically produce and secrete higher levels of pro-inflammatory cytokines TNF- $\alpha$, interleukin (IL)-1, IL-6, IL-12 and iNOS. M2 macrophages negatively regulate proinflammatory cytokines and induce the production of anti-inflammatory mediators, such as interleukin (IL)-4, IL-10 and TGF- $\beta$ (8-10). Research has shown that TAM density correlates with poor prognosis in clinical studies (11). The roles of TAMs in stimulating tumor growth, invasion, angiogenesis, metastasis and immunosuppression have been reviewed extensively (12-14). Studies have also shown that the products of tumor cells are involved in the differentiation into M2 macrophages by secreting IL-10 
and activating nuclear factor erythroid 2-related factor 2 (15), however, the mechanisms that link tumor cells and TAMs remain to be fully elucidated.

Transcriptional profiling is a useful tool for determining the general patterns of differential gene expression among samples (16). RNA-Seq is highly sensitive and can quantitatively measure gene expression over a large dynamic range of transcript abundances (17). Proteomics reveals not only information on the individual components (i.e., proteins) in a cell, but also on their interplay in complexes, signaling pathways and network modules associated with specific biochemical functions (18). The abundance of proteins, or peptides, in complex biological samples can be assessed by liquid chromatography coupled with mass spectrometry (LC-MS) (19). Alternatively, label-free quantitative proteomics, which is increasing in popularity, provides a cost-effective alternative to labeled quantification (20). The present study examined the relationships between tumor cells and macrophages and attempted to elucidate the mechanisms directing macrophage differentiation using high-throughput omic technologies.

\section{Materials and methods}

Cell culture. Two types of cells were used in the experiments. SKOV3 (ATCC) cells were grown in DMEM (Thermo Fisher Scientific, Inc.) supplemented with $10 \%$ fetal bovine serum (FBS; Biological Industries) and THP-1 (ATCC) cells were grown in RPMI 1640 medium (Thermo Fisher Scientific, Inc.), supplemented with 2-mercaptoethanol to a final concentration of $0.05 \mathrm{mM}$ and $10 \%$ FBS. The cells were maintained at $37^{\circ} \mathrm{C}$ in a humidified atmosphere in an incubator containing $5 \% \mathrm{CO}_{2}$. The THP-1 cells were differentiated into M0 macrophages by incubation for $48 \mathrm{~h}$ with $100 \mathrm{ng} / \mathrm{ml}$ phorbol 12-myristate 13-acetate (PMA, Sigma-Aldrich; Merck KGaA). The M0 macrophages were polarized into M1 macrophages by incubation with $20 \mathrm{ng} / \mathrm{ml}$ of lipopolysaccharide (LPS; Santa Cruz Biotechnology, Inc.) for 48 h. M2 macrophage polarization was obtained by incubation with $20 \mathrm{ng} / \mathrm{ml}$ of IL-4 (ProteinTech Group, Inc.) for $48 \mathrm{~h}$.

Collection of conditioned media (CM). The SKOV3 cells, apoptotic SKOV3 cells, M0 macrophages and M2 macrophages were inoculated into Petri dishes at a density of $2 \times 10^{5} / \mathrm{ml}$ with FBS-free DMEM. The CM was collected following 4, 8, 12 and $24 \mathrm{~h}$ of incubation and was centrifuged ( $800 \times \mathrm{g}$ for $3 \mathrm{~min}$ at room temperature) to remove cells and debris. We obtained SKOV3 CM, DS CM, M0 CM and M2 CM. The M0 macrophages were co-cultured with apoptotic or non-apoptotic SKOV3 cells at a ratio of 1:1 and a density of $2 \times 10^{5} / \mathrm{ml}$. Following the same procedure as above, we obtained M0-SKOV3 CM and M0-DS CM. The M0 macrophages were treated with $5 \mu \mathrm{M}$ of PD98059 (Bimake) for $48 \mathrm{~h}$ and co-cultured with apoptotic SKOV3 cells following treatment with PD98059. Following the same aforementioned procedure, the present study obtained M0-PD CM and M0-PD-DS CM.

Cell counting kit-8 (CCK-8) assay. The SKOV3 cells were plated at a density of $5 \times 10^{3}$ cells/well in 96 well plates, and cell viability was assessed using the CCK- 8 assay according to the manufacturer's instructions. Following treatment for 12, 24,
36 and 48 h, CCK-8 (Vazyme, Nanjing, China) reagent (10 $\mu \mathrm{l})$ was added to each well followed by incubation for $2 \mathrm{~h}$ at $37^{\circ} \mathrm{C}$. The OD values of each well were measured at $450 \mathrm{~nm}$ using a microplate reader.

Assayforcellularapoptosis. The Annexin V-FITC/PI Apoptosis Detection kit (Beijing Solarbio Science \& Technology Co., Ltd., Beijing, China) was used according to the manufacturer's instructions. The SKOV3 cells were treated with DDP for $24 \mathrm{~h}$, and then collected and washed twice with PBS. The cells were then resuspended in $200 \mu \mathrm{l}$ binding buffer with $10 \mu \mathrm{l}$ Annexin V-FITC and $10 \mu \mathrm{l}$ PI, gently mixed and incubated for $15 \mathrm{~min}$ in the dark at room temperature. Binding buffer (300 $\mu \mathrm{l})$ was added to each tube and the samples were analyzed by flow cytometry (FACSCalibur; BD Biosciences) within $1 \mathrm{~h}$.

Transwell migration assays. Migration was assessed using Transwell chambers (24-well, 8.0- $\mu \mathrm{m}$ pore membranes, Corning Inc., Corning, NY, USA), which were used according to the manufacturer's protocol. The cells $\left(1 \times 10^{5}\right.$ per well) were seeded into the upper chamber in $100 \mu \mathrm{l}$ of FBS-free CM, and $600 \mu \mathrm{l}$ of $20 \%$ FBS CM was added to the lower chamber as a chemoattractant. Following incubation for $36 \mathrm{~h}$ at $37^{\circ} \mathrm{C}$, the cells remaining on the upper surface of the membrane were removed with cotton swabs, whereas cells on the lower surface of the membrane were considered migrated cells. Following fixing with $4 \%$ paraformaldehyde for $10 \mathrm{~min}$ at room temperature, the cells were stained with $0.1 \%$ crystal violet solution (Sigma-Aldrich; Merck KGaA) for 15 min at room temperature. Images of the cells that had passed through the filter were captured using an inverted fluorescence microscope and the cells were counted.

Immunofluorescence. The cells were washed with cold PBS and fixed with paraformaldehyde. After blocking with 5\% bovine serum albumin (Sigma Aldrich; Merck KGaA) for $2 \mathrm{~h}$ at room temperature, the fixed cells were then incubated with primary anti-CD163 (cat. no. ab87099), anti-CD68 (cat. no. ab201973), anti-CD204 (cat. no. ab36998) and anti-CD206 (cat. no. ab64693) (all 1:200; all from Abcam) overnight at $4{ }^{\circ} \mathrm{C}$. The cells were then washed with cold PBS and incubated with fluorophore-conjugated secondary antibody (goat anti-rabbit IgG; cat. no. ZF-0311 and goat anti-mouse IgG; cat. no. ZF-0313; both 1:50; both from Zsbio, OriGene Technologies, Inc., Beijing, China) at $37^{\circ} \mathrm{C}$ for $1 \mathrm{~h}$. The nuclei were stained with DAPI (Beijing Solarbio Science \& Technology Co., Ltd.) for $20 \mathrm{~min}$ at room temperature. Finally, the cells were washed with cold PBS and observed using a laser confocal microscope (TCS-SP8 STED 3X; Leica).

Isolation of total RNA and reverse transcription-quantitative $(R T-q) P C R$ analysis. Total RNA was isolated using TRIzol reagent (Thermo Fisher Scientific, Inc., Waltham, MA, USA) according to the manufacturer's instructions. cDNA was synthesized from $1 \mu \mathrm{g}$ of total RNA using a high capacity cDNA reverse transcription kit (Thermo Fisher Scientific, Inc.) according to the manufacturer's protocol. Amplifications were performed in the StepOne ${ }^{\mathrm{TM}}$ Real-Time PCR system using PowerUp ${ }^{\mathrm{TM}} \mathrm{SYBR}^{\circledR}$-Green Master mix (Applied Biosystems; Thermo Fisher Scientific, Inc.) with primers listed in Table I. 
Table I. Primers used for reverse transcription-quantitative PCR analysis of gene expression.

\begin{tabular}{|c|c|}
\hline Gene & Primer (5'-3') \\
\hline \multirow[t]{2}{*}{ IL10 } & F-GTGATGCCCCAAGCTGAGA \\
\hline & R-CACGGCCTTGCTCTTGTTTT \\
\hline \multirow[t]{2}{*}{ CCL22 } & F-TCCTCGTCCTCCTTGCTGT \\
\hline & R-GGTCCAGTAGAAGTGTTTCACCA \\
\hline \multirow[t]{2}{*}{ iNOS } & F-CGCATGACCTTGGTGTTTGG \\
\hline & R-CATAGACCTTGGGCTTGCCA \\
\hline \multirow[t]{2}{*}{ IL12 } & F-ССТСАСССССАССТСТСТАА \\
\hline & R-GGGCTGTTAAGAAGCCACCT \\
\hline \multirow[t]{2}{*}{ ANPEP } & F-CTGTGAGCCAGTCTAGTTCCTGAT \\
\hline & R-CATCGAGAGCTTCTGCTCATCT \\
\hline \multirow[t]{2}{*}{ DAB2 } & F-GGGCATTTGGTTACGTGTG \\
\hline & R-CTTTGCTGGCTTCCTCTATC \\
\hline \multirow[t]{2}{*}{ CSF1 } & F-TGCAGCGGCTGATTGACA \\
\hline & R-GATCTTTCAACTGTTCCTGGTCTACA \\
\hline \multirow[t]{2}{*}{ NT5E } & F-TGGAGATGGGTTCCAGATGATAA \\
\hline & R-GGATAAATTACTTTCATTTTGGAGATATATGTA \\
\hline \multirow[t]{2}{*}{ ITGAM } & F-GTGAAGCCAATAACGCAGC \\
\hline & R-TCTCCATCCGTGATGACAAC \\
\hline \multirow[t]{2}{*}{ MMP1 } & F-GGGAGATCATCGGGACAACTC \\
\hline & R-GGGCCTGGTTGAAAAGCAT \\
\hline \multirow[t]{2}{*}{ GAPDH } & F-GCACCGTCAAGGCTGAGAAC \\
\hline & R-TGGTGAAGACGCCAGTGGA \\
\hline
\end{tabular}

F, forward; R, reverse; IL, interleukin; CCL22, C-C motif chemokine ligand 22; iNOS, inducible nitric oxide synthase; ANPEP, aminopeptidase-N; DAB2, disabled homolog 2; CSF1, colony-stimulating factor 1; NT5E, 5'-nucleotidase; ITGAM, integrin $\alpha$-M; MMP1, matrix metalloproteinase 1 .

Amplification was initiated at $95^{\circ} \mathrm{C}$ for $30 \mathrm{sec}$, followed by 40 cycles of qPCR at $95^{\circ} \mathrm{C}$ for $5 \mathrm{sec}$ (denaturation) and at $60^{\circ} \mathrm{C}$ for $15 \mathrm{sec}$ (annealing/extension). The transcription levels were normalized to those of GAPDH. The formula $2^{-\Delta \Delta \mathrm{Cq}}$ was implemented to analyze the mRNA expression levels, where $\Delta \Delta \mathrm{Ct}=\left(\mathrm{Ct}_{\text {target }}-\mathrm{Ct}_{\mathrm{GAPDH}}\right)_{\text {sample }}-\left(\mathrm{Ct}_{\text {target }}-\mathrm{Ct}_{\mathrm{GAPDH}}\right)_{\text {control }}(21)$.

RNA-Seq analysis. A total of $3 \mu \mathrm{g}$ of RNA per sample was used as the input for RNA sample preparations. Sequencing libraries were generated using the NEBNext ${ }^{\circledR}$ UltraTM RNA Library Prep kit for Illumina ${ }^{\circledR}$ (New England BioLabs, Inc., Ipswich, MA, USA) following the manufacturer's recommendations, and index codes were added to attribute sequences to the samples. Clustering of the index-coded samples was performed on a cBot Cluster Generation system using TruSeq PE Cluster kit v3-cBot-HS (Illumina, Inc.) according to the manufacturer's instructions. Following cluster generation, library preparations were sequenced on an Illumina Hiseq platform and 125/150-bp paired-end reads were generated. The raw data (raw reads) in fastq format were first processed through in-house perl scripts. Clean data (clean reads) were obtained by removing reads containing adapters, reads containing ploy- $\mathrm{N}$ or low-quality reads from raw data. Reference genome and gene model annotation files were downloaded directly from the Ensembl genome website (ftp://ftp.ensembl.org/pub/release-90/gtf/homo_ sapiens/Homo_sapiens.GRCh38.90.gtf.gz). An index of the reference genome was built using Hisat2 v2.0.5 (http://ccb. jhu.edu/software/hisat2/index.shtml) and paired-end clean reads were aligned to the reference genome using Hisat2 v2.0.5. Feature Counts v1.5.0-p3 (http://subread.sourceforge. net) was used to count the number of reads mapped to each gene. The Fragments Per Kilobase of transcript sequence per Millions base pairs sequenced (FPKM) for each gene was calculated based on the length of the gene and the count of the reads mapped to this gene. Prior to differential gene expression analysis, for each sequence library, the read count numbers were adjusted using the edgeR program package (version 3.6; http://www.bioconductor.org/packages/release/bioc/html/edgeR.html) through one scaling normalized factor. Differential expression analysis of the two conditions was performed using the edgeR $\mathrm{R}$ package. P-values were adjusted using the Benjamini \& Hochberg method for multiple testing. A corrected P-value of 0.05 and an absolute fold-change of 2 were set as the thresholds for significant differential expression.

Shotgun proteomic analysis. Proteins were extracted with RIPA lysis buffer (Applygen Technologies, Inc., Beijing, China) containing a protease inhibitor cocktail (Bimake, Houston, TX, USA) and a phosphatase inhibitor cocktail (Bimake). Protein concentration was measured with the BCA kit (Dingguo Changsheng Biotechnology Co., Ltd., Beijing, China). Protein samples (200 $\mu \mathrm{g})$ from each group were processed according to the manufacturer's protocol for filter-aided sample preparation. The protein concentrates in a Vivacon 500 filtrate tube (cat. no. VNO1HO2; Sartorius Stedim Biotech, Göttingen, Germany) were mixed with $100 \mu \mathrm{l}$ of $8 \mathrm{M}$ urea in $0.1 \mathrm{M}$ Tris/HCL ( $\mathrm{pH} 8.5$ ) and then samples were centrifuged at $14,000 \mathrm{~g}$ at $20^{\circ} \mathrm{C}$ for $15 \mathrm{~min}$. This step was performed twice, following which $10 \mu \mathrm{l}$ of $0.05 \mathrm{M}$ Tris-(2-carboxyethyl) phosphine in water was added to the filters, and the samples were incubated at $37^{\circ} \mathrm{C}$ for $1 \mathrm{~h}$. Subsequently, $10 \mu 1$ of $0.1 \mathrm{M}$ iodoacetamide was added to the filters and the samples were incubated in the dark for $30 \mathrm{~min}$. The filters were washed twice with $200 \mu \mathrm{l}$ of $50 \mathrm{mM} \mathrm{NH} \mathrm{HCO}_{3}$. Finally, $4 \mu \mathrm{g}$ of trypsin (Promega Corporation, Madison, WI, USA) in $100 \mu \mathrm{l}$ of $50 \mathrm{mM} \mathrm{NH}_{4} \mathrm{HCO}_{3}$ was added to each filter. The protein to enzyme ratio was 50:1. The samples were incubated overnight at $37^{\circ} \mathrm{C}$ and the peptides released were collected following centrifugation three times $\left(12,000 \mathrm{xg}\right.$ for $15 \mathrm{~min}$ at $\left.15^{\circ} \mathrm{C}\right)$. The experiments were performed in triplicate.

High $\mathrm{pH}$ reverse-phase chromatography was performed using the Dionex Ultimate 3000 Micro Binary HPLC Pump system. The digested peptide mixture was reconstituted with $600 \mu \mathrm{l}$ buffer $\mathrm{A}$ ( $20 \mathrm{mM}$ ammonium formate in water, $\mathrm{pH} 10$ ) and loaded onto a $2.1 \times 150 \mathrm{~mm}$ Waters BEH130 C-18 column with $3.5-\mu \mathrm{m}$ particles. The peptides were eluted at a flow rate of $230 \mu \mathrm{l} / \mathrm{min}$ with a gradient of $5 \%$ buffer B $(20 \mathrm{mM}$ ammonium formate in $80 \%$ acetonitrile, $\mathrm{pH} 10$ ) for $5 \mathrm{~min}, 5-15 \%$ buffer $\mathrm{B}$ for $15 \mathrm{~min}, 15-25 \%$ buffer B for $10 \mathrm{~min}, 25-55 \%$ buffer B for $10 \mathrm{~min}$ and $55-95 \%$ buffer $\mathrm{B}$ for $5 \mathrm{~min}$. The system was then maintained in $95 \%$ buffer B for 5 min before equilibrating 

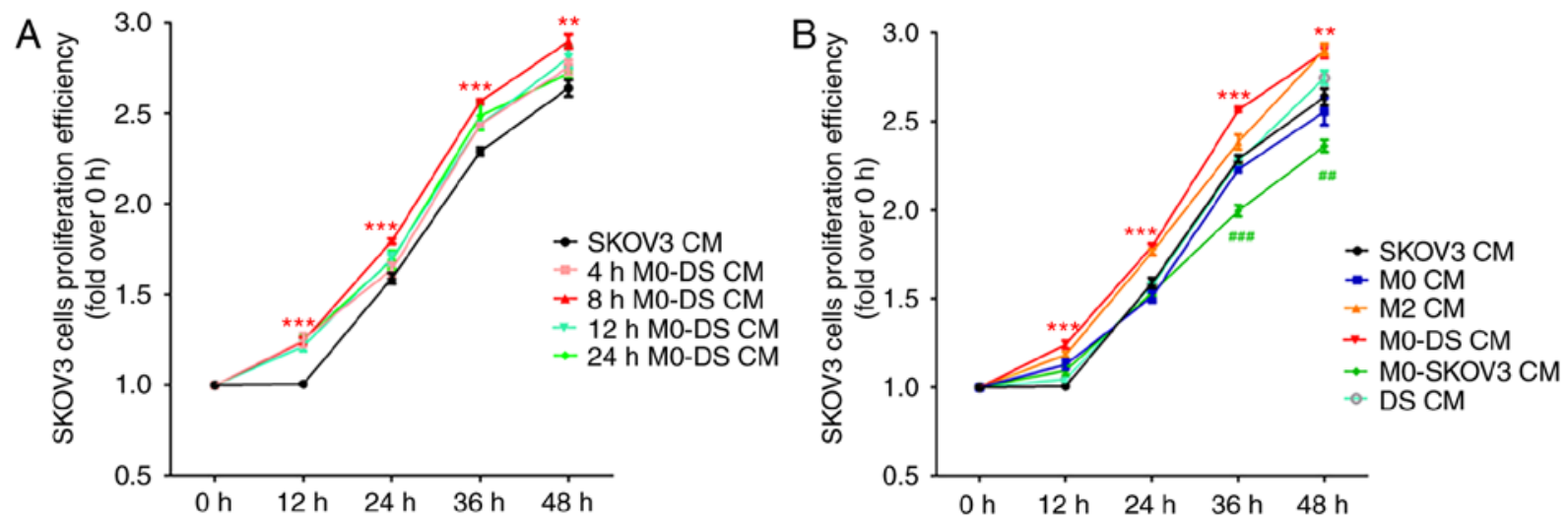

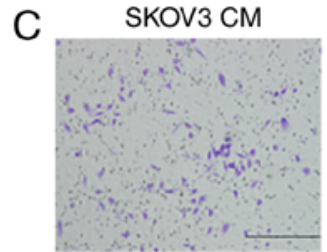

MO-DS CM

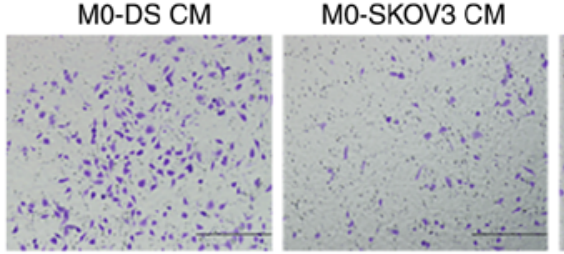

M2 CM
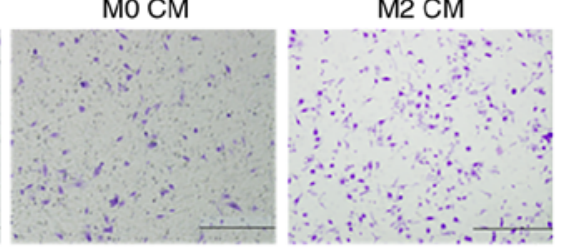

DS CM

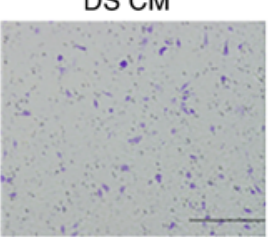

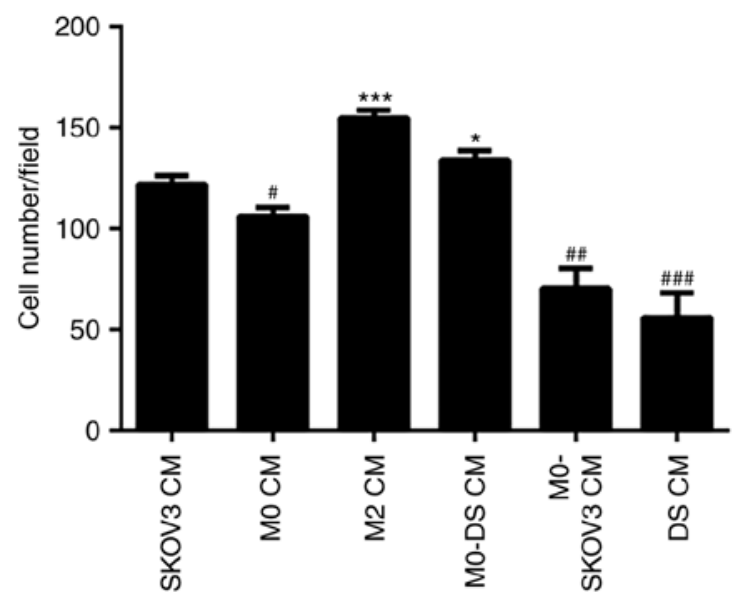

Figure 1. Proliferation and migration of SKOV3 cells. (A) Proliferative ability, measured using a CCK-8 assay, of SKOV3 cells cultured in CM from SKOV3 cells (SKOV3 CM) or the co-culture of apoptotic SKOV3 cells and macrophages (M0-DS CM) for different periods of time (4-24 h). (B) Proliferative ability, measured using a CCK-8 assay, of SKOV3 cells cultured in CM from SKOV3 cells, M0 macrophages, M2 macrophages, macrophages co-cultured with apoptotic or non-apoptotic SKOV3 cells, or apoptotic SKOV3 cells only. (C) Transwell assay examining the migration ability of the SKOV3 cells in the six CM groups. Scale bar, $500 \mu \mathrm{m}$. Results are typical of three independent experiments. Data are presented as the mean $\pm \mathrm{SD}(\mathrm{n}=3$ ). Intergroup differences were analyzed using one-way ANOVA. Tukey's post hoc test was used for the multiple comparisons among the various groups. ${ }^{*} \mathrm{P}<0.05,{ }^{* * *} \mathrm{P}<0.01$ and ${ }^{* * * *} \mathrm{P}<0.001$ vs. SKOV3 CM group; ${ }^{\#} \mathrm{P}<0.05,{ }^{\# \#} \mathrm{P}<0.01$ and ${ }^{\# \#} \mathrm{P}<0.001$ vs. SKOV3 CM group. CCK-8, Cell counting kit-8; CM, conditioned media; DS, apoptotic SKOV3 cells.

with $5 \%$ buffer B for 10 min prior to the next injection. Elution was monitored by measuring the absorbance at $214 \mathrm{~nm}$ and fractions were collected every $2 \mathrm{~min}$. The eluted peptides were pooled into 15 fractions and vacuum-dried. The samples were then ready for nano-ESI-LCMS/MS analysis.

The LC-MS experiments were performed on a nano-flow HPLC system (Easy-nLC II, Thermo Fisher Scientific, Inc.) connected to a linear quadrupole ion trap (LTQ)-Orbitrap Velos Pro mass spectrometer (Thermo Fisher Scientific), equipped with a Nanospray Flex ion source (Thermo Fisher Scientific). The peptide mixtures $(5 \mu \mathrm{l})$ were injected at a flow rate of $5 \mu \mathrm{l} / \mathrm{min}$ onto a pre-column (Easy-column C18-A1, $100 \mu \mathrm{m}$ I.D.x20 mm, $5 \mu \mathrm{m}$, Thermo Fisher Scientific, Inc.). Chromatographic separation was performed on a reversed-phase C18 column (Easy-column C18-A2, $75 \mu \mathrm{m}$ I.D. x100 mm, $3 \mu \mathrm{m}$, Thermo Fisher Scientific, Inc.) at a flow rate of $300 \mathrm{nl} / \mathrm{min}$ with a 60 min gradient of $2-40 \%$ acetonitrile in $0.1 \%$ formic acid. The electrospray voltage was maintained at $2.2 \mathrm{kV}$, and the capillary temperature was set at $250^{\circ} \mathrm{C}$. The LTQ-Orbitrap was operated in data-dependent mode to simultaneously measure the full scan MS spectra (350-2,000 m/z) in the Orbitrap with a mass resolution of 60,000 at $400 \mathrm{~m} / \mathrm{z}$. Following the full-scan survey, the 15 most abundant ions detected in the full MS scan were measured in the LTQ-Orbitrap using collision-induced dissociation.
Data analysis was performed with MaxQuant software (version 1.4.1.2; http://www.maxquant.org). For protein identification, the MS/MS data were submitted to the Uniprot human protein database (http://www.uniprot.org; release 3.43; 72,340 sequences) using the Andromeda search engine with the following settings: Trypsin cleavage; fixed modification of carbamido-methylation of cysteine; variable modifications of methionine oxidation; a maximum of two missed cleavages; and false discovery rate was calculated by decoy database searching. All other parameters were set as default. The results were imported into Microsoft Excel (Microsoft Corporation) for further analysis. Label-free quantitation (LFQ) was also performed in MaxQuant. The minimum ratio count for LFQ was set to 2, and the match-between-runs option was enabled. All other parameters were set as default. The upregulated or downregulated proteins were defined as those with a significantly altered protein ratio $(\mathrm{P}<0.05)$. A 2 -fold change in expression and $\mathrm{P}=0.05$ were used as a combined threshold to define biologically regulated proteins.

Western blot analysis. Following the addition of sample loading buffer, the $40 \mu \mathrm{g}$ of protein samples per lane were separated using 10\% SDS-PAGE and subsequently transferred onto a PVDF membrane (Bio-Rad Laboratories, Inc., 
Table II. Differentially expressed proteins and genes revealed by LC-MS/MS and RNA-Seq.

\begin{tabular}{|c|c|c|c|c|c|}
\hline \multirow[b]{2}{*}{ Gene name } & \multirow[b]{2}{*}{ Protein name } & \multicolumn{2}{|c|}{ LC-MS/MS } & \multicolumn{2}{|c|}{ RNA-Seq } \\
\hline & & $\begin{array}{c}\text { Ratio } \\
\text { (M2/M0) }\end{array}$ & $\begin{array}{l}-\log 10 \\
\text { P-value }\end{array}$ & $\begin{array}{c}\text { Ratio } \\
\text { (M2/M0) }\end{array}$ & $\begin{array}{c}-\log 10 \\
\text { P-value }\end{array}$ \\
\hline APOE & Apolipoprotein E & 11.90 & 2.29 & 2.77 & 1.59 \\
\hline LPL & Lipoprotein lipase & 12.03 & 2.89 & 4.79 & 2.40 \\
\hline HSD11B1 & Corticosteroid $11-\beta$-dehydrogenase isozyme 1 & 3.90 & 2.13 & 4.89 & 2.35 \\
\hline MGLL & Monoglyceride lipase & 42.53 & 1.34 & 3.17 & 1.74 \\
\hline NPC1 & Niemann-Pick C1 protein & 2.42 & 2.39 & 3.19 & 1.80 \\
\hline LRP12 & Low-density lipoprotein receptor-related protein 12 & 5.22 & 2.79 & 2.78 & 1.55 \\
\hline ITGAM & Integrin $\alpha-\mathrm{M}$ & 2.88 & 3.45 & 3.66 & 2.01 \\
\hline ITGAX & Integrin $\alpha-X$ & 2.25 & 3.82 & 2.41 & 1.36 \\
\hline ITGB3 & Integrin $\beta-3$ & 6.38 & 2.48 & 4.04 & 1.99 \\
\hline ANPEP & Aminopeptidase $\mathrm{N}$ & 6.65 & 4.37 & 4.25 & 2.24 \\
\hline CD83 & CD83 antigen & 17.72 & 2.54 & 2.72 & 1.54 \\
\hline CSF1 & Macrophage colony-stimulating factor 1 & 12.30 & 4.56 & 2.59 & 1.49 \\
\hline NT5E & 5-nucleotidase & 4.24 & 2.26 & 2.85 & 1.59 \\
\hline NES & Nestin & 8.04 & 2.31 & 3.14 & 1.76 \\
\hline UPP1 & Uridine phosphorylase 1 & 14.36 & 4.39 & 3.81 & 2.07 \\
\hline MMP1 & Interstitial collagenase & 6.81 & 3.10 & 4.57 & 2.30 \\
\hline TIMP1 & Metalloproteinase inhibitor 1 & 8.45 & 4.14 & 3.49 & 1.95 \\
\hline TIMP3 & Metalloproteinase inhibitor 3 & 5.62 & 3.68 & 2.97 & 1.70 \\
\hline CTSL & Cathepsin L1 & 2.65 & 1.71 & 3.70 & 2.03 \\
\hline QSOX1 & Sulfhydryl oxidase 1 & 3.04 & 1.55 & 2.64 & 1.52 \\
\hline HMOX1 & Heme oxygenase 1 & 8.68 & 3.00 & 3.54 & 1.95 \\
\hline CTTN & Src substrate cortactin & 18.50 & 2.89 & 3.65 & 1.89 \\
\hline DAB2 & Disabled homolog 2 & 3.48 & 1.67 & 2.99 & 1.66 \\
\hline CHIT1 & Chitotriosidase-1 & 16.98 & 1.40 & 2.78 & 1.51 \\
\hline COL6A2 & Collagen $\alpha-2(\mathrm{VI})$ chain & 4.46 & 2.25 & 4.79 & 2.41 \\
\hline EGR2 & E3 SUMO-protein ligase EGR2 & 12.29 & 2.74 & 2.99 & 1.70 \\
\hline FRMD4A & FERM domain-containing protein 4A & 7.64 & 2.29 & 4.14 & 2.14 \\
\hline G6PD & Glucose-6-phosphate 1-dehydrogenase & 3.22 & 4.05 & 2.69 & 1.54 \\
\hline GDF15 & Growth/differentiation factor 15 & 7.07 & 2.37 & 2.48 & 1.42 \\
\hline MFSD12 & Major facilitator superfamily domain-containing protein 12 & 5.43 & 1.60 & 2.77 & 1.59 \\
\hline MGAT1 & $\alpha-1,3$-mannosyl-glycoprotein $2-\beta-\mathrm{N}$-acetylglucosaminyltransferase & 2.02 & 1.42 & 2.69 & 1.55 \\
\hline IL4I1 & L-amino-acid oxidase & 3.90 & 3.47 & 3.61 & 1.99 \\
\hline OGFRL1 & Opioid growth factor receptor-like protein 1 & 4.52 & 3.10 & 3.15 & 1.77 \\
\hline PLEK & Pleckstrin & 2.46 & 2.00 & 3.21 & 1.82 \\
\hline PTPRE & Receptor-type tyrosine-protein phosphatase epsilon & 2.23 & 2.73 & 2.41 & 1.34 \\
\hline RBM47 & RNA-binding protein 47 & 2.81 & 1.62 & 3.21 & 1.75 \\
\hline SLC20A1 & Sodium-dependent phosphate transporter 1 & 3.97 & 3.03 & 2.42 & 1.37 \\
\hline SLC27A3 & Long-chain fatty acid transport protein 3 & 6.17 & 1.47 & 2.93 & 1.65 \\
\hline SLC5A3 & Sodium/myo-inositol cotransporter & 6.72 & 2.06 & 3.31 & 1.83 \\
\hline TBC1D2 & TBC1 domain family member $2 \mathrm{~A}$ & 4.85 & 1.39 & 3.23 & 1.75 \\
\hline TSC22D1 & TSC22 domain family protein 1 & 5.02 & 1.86 & 2.48 & 1.41 \\
\hline TTC39B & Tetratricopeptide repeat protein 39B & 3.52 & 2.94 & 3.81 & 1.88 \\
\hline $\mathrm{ZCCHC} 2$ & Zinc finger $\mathrm{CCHC}$ domain-containing protein 2 & 3.27 & 1.69 & 2.95 & 1.66 \\
\hline ANLN & Actin-binding protein anillin & 0.00 & 1.50 & 0.34 & 1.39 \\
\hline CENPE & Centromere-associated protein $\mathrm{E}$ & 0.00 & 3.62 & 0.19 & 1.85 \\
\hline DIAPH3 & Protein diaphanous homolog 3 & 0.00 & 1.69 & 0.35 & 1.32 \\
\hline $\mathrm{ESCO} 2$ & $\mathrm{~N}$-acetyltransferase ESCO2 & 0.00 & 1.99 & 0.36 & 1.31 \\
\hline KIF14 & Kinesin-like protein KIF14 & 0.00 & 2.04 & 0.27 & 1.58 \\
\hline LRMP & Lymphoid-restricted membrane protein & 0.33 & 1.83 & 0.23 & 2.07 \\
\hline MMS22L & Protein MMS22-like & 0.21 & 1.63 & 0.33 & 1.40 \\
\hline
\end{tabular}


Table II. Continued.

\begin{tabular}{|c|c|c|c|c|c|}
\hline \multirow[b]{2}{*}{ Gene name } & \multirow[b]{2}{*}{ Protein name } & \multicolumn{2}{|c|}{ LC-MS/MS } & \multicolumn{2}{|c|}{ RNA-Seq } \\
\hline & & $\begin{array}{c}\text { Ratio } \\
(\mathrm{M} 2 / \mathrm{M} 0)\end{array}$ & $\begin{array}{l}-\log 10 \\
\text { P-value }\end{array}$ & $\begin{array}{c}\text { Ratio } \\
(\mathrm{M} 2 / \mathrm{M} 0)\end{array}$ & $\begin{array}{l}-\log 10 \\
\text { P-value }\end{array}$ \\
\hline PKMYT1 & $\begin{array}{l}\text { Membrane-associated tyrosine- and threonine-specific } \\
\text { cdc2-inhibitory kinase }\end{array}$ & 0.00 & 2.41 & 0.38 & 1.44 \\
\hline PPP1R27 & Protein phosphatase 1 regulatory subunit 27 & 0.00 & 1.38 & 0.21 & 2.37 \\
\hline SMC2 & Structural maintenance of chromosomes protein 2 & 0.44 & 3.18 & 0.27 & 1.72 \\
\hline SMC4 & Structural maintenance of chromosomes protein 4 & 0.40 & 1.86 & 0.28 & 1.89 \\
\hline TGFBR1 & TGF- $\beta$ receptor type- 1 & 0.00 & 1.41 & 0.35 & 1.62 \\
\hline
\end{tabular}

LC-MS, liquid chromatography coupled with mass spectrometry.

Hercules, CA, USA). The membrane was incubated in fresh blocking buffer at room temperature for $1 \mathrm{~h}$ and then incubated with anti-Erk1/2 antibody (cat. no. 4695; Cell Signaling Technology, Inc.; 1:1,000), anti-phospho-Erk1/2 (cat no. 4370; Cell Signaling Technology, Inc.; 1:1,000) and anti-GAPDH antibody (cat. no. ab8245; Abcam; 1:5,000) in blocking buffer at $4^{\circ} \mathrm{C}$ overnight. The membrane was washed three times for 5 min each time using PBST, and then incubated with the appropriate horseradish peroxidase-conjugated secondary antibody (cat. no. ZB-2301; Zsbio, OriGene Technologies, Inc.; 1:1,000) at room temperature for $1 \mathrm{~h}$. The proteins were detected by enhanced chemiluminescence (Applygen Technologies, Inc.) and band intensity was quantified with Quantity One software (version 4.4; Bio-Rad Laboratories, Inc.).

Bioinformatics analysis. Differentially expressed genes and proteins were analyzed using the Database for Visualization and Integrated Discovery (DAVID; version 6.8; https://david.ncifcrf. gov) to obtain Gene Ontology (GO) enrichments. A protein interaction network of the differentially expressed proteins was deduced using the Search Tool for the Retrieval of Interactinv Genes/Proteins (STRING; version 11.0; https://string-db.org). All detected proteins and their expression levels were analyzed using gene set enrichment analysis (GSEA; version 3.0; http://www.gsea-msigdb.org/gsea/index.jsp). The gene set database was c2.cp.kegg.v6.1.symbols.gmt, with 1,000 permutations and collapse dataset to gene symbols set as true.

Statistical analysis. Data are presented as the mean \pm standard deviation. Statistical analyses were performed with SPSS 19.0 (IBM Corp, Armonk, NY USA). Intergroup differences were analyzed using one-way ANOVA. Tukey's post hoc test was used for the multiple comparisons among the various groups. $\mathrm{P}<0.05$ was considered to indicate a statistically significant difference.

\section{Results}

Apoptotic SKOV3-stimulated MO and M2 macrophages promote the proliferation and migration of SKOV3 cells. M0 macrophages were generated by stimulating THP-1 cells with PMA for $48 \mathrm{~h}$ and then allowing the cells to attach to dishes and differentiate (22). The M0 macrophages were differentiated into M2 macrophages by incubation with IL 4 for $48 \mathrm{~h}$ (23). These M0 macrophages were then co-cultured with apoptotic or non-apoptotic SKOV3 cells at a ratio of 1:1 for $8 \mathrm{~h}$, and the $\mathrm{CM}$ generated from these co-cultures was collected. DDP, which is toxic to cells, was used to induce apoptosis in SKOV3 cells (24). The levels of apoptosis induced by DDP were examined using flow cytometry following PI-Annexin V co-staining of the cells. SKOV3 cells treated with $40 \mu \mathrm{M}$ DDP for $24 \mathrm{~h}$ generated the maximum apoptotic effect, with almost $100 \%$ apoptosis (Fig. S1). All subsequent experiments used $40 \mu \mathrm{M}$ DDP for 24 h to generate apoptotic SKOV3 cells. The SKOV3 cells were cultured with several different types of CM (with the addition of $10 \%$ FBS), including media conditioned by SKOV3 only (SKOV3 CM), by M0 macrophages only (M0 CM), by M2 macrophages only (M2 CM), by macrophages co-cultured with apoptotic SKOV3 cells (M0-DS CM), by macrophages co-cultured with SKOV3 cells (M0-SKOV3 CM), and by apoptotic SKOV3 cells only (DS CM). It was found that the proliferative capacity of the SKOV3 cells was significantly increased in MO-DS CM compared with that in SKOV3 CM, and the maximum effect was observed following co-culture for $8 \mathrm{~h}$ (Fig. 1A). Therefore, a co-culture duration of $8 \mathrm{~h}$ was used for subsequent experiments. It was found that the proliferative capacity of the SKOV3 cells was also significantly increased in M2 CM compared with that in SKOV3 CM. No significant changes in proliferative ability were observed in the M0 CM or DS CM groups compared with that in the SKOV3 CM group, however, the proliferative ability of SKOV3 cells was lower in the M0-SKOV3 CM group compared with that in the SKOV3 CM group (Fig. 1B). A Transwell experiment was then performed to examine the ability of SKOV3 cells to migrate. The ability of the SKOV3 cells to migrate was enhanced with M2 CM and M0-DS CM compared with that with SKOV3 CM, whereas the migration abilities of SKOV3 cells in the M0 CM, M0-SKOV3 CM and DS CM groups were decreased (Fig. 1C). These results suggest that apoptotic SKOV3-stimulated M0 macrophages tend to differentiate into M2 macrophages.

Differential expression of $m R N A$ s, proteins and pathways in MO and M2 macrophages assessed by RNA-Seq and quantitative proteomic analysis. As a first step in determining whether 
A

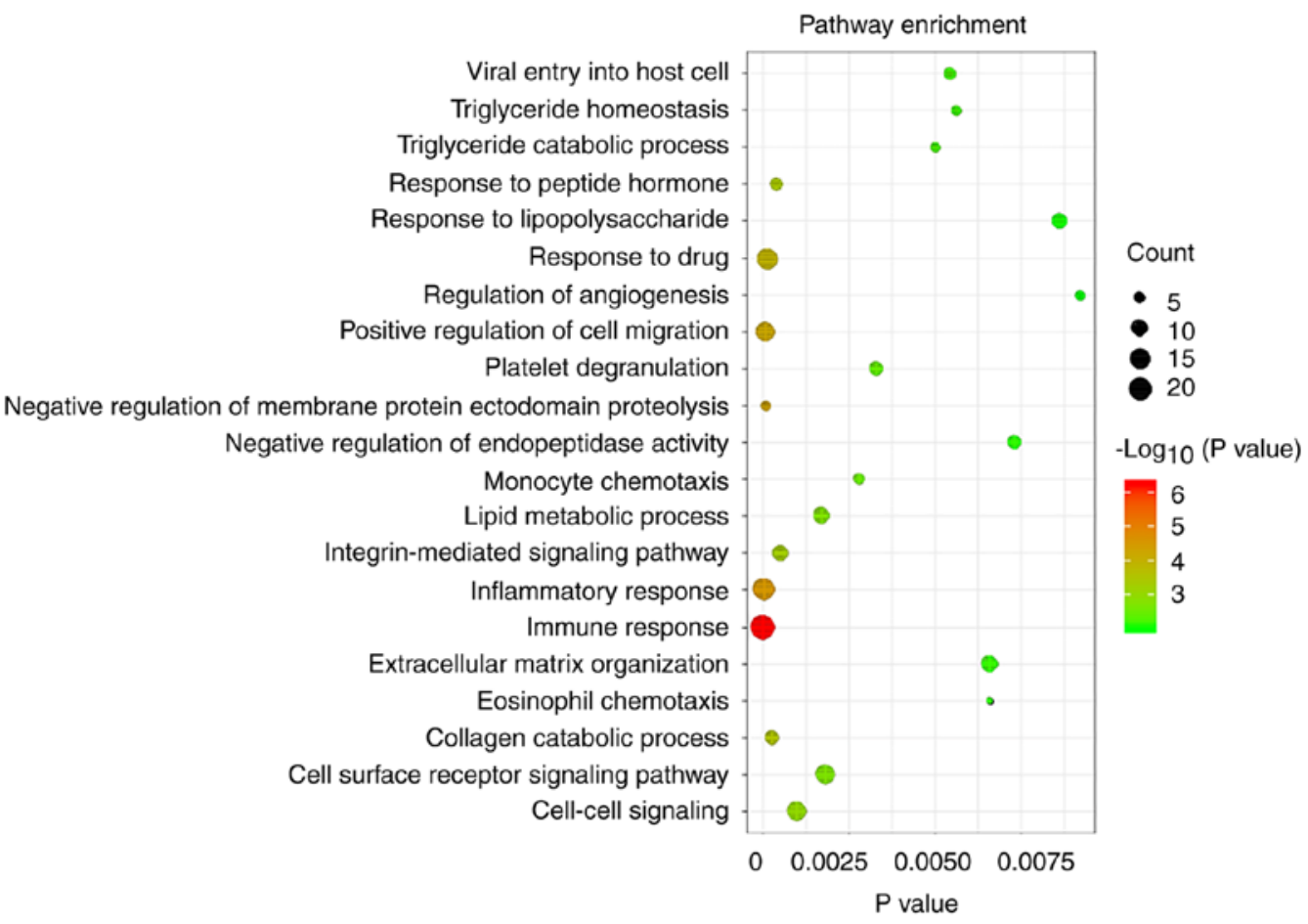

B

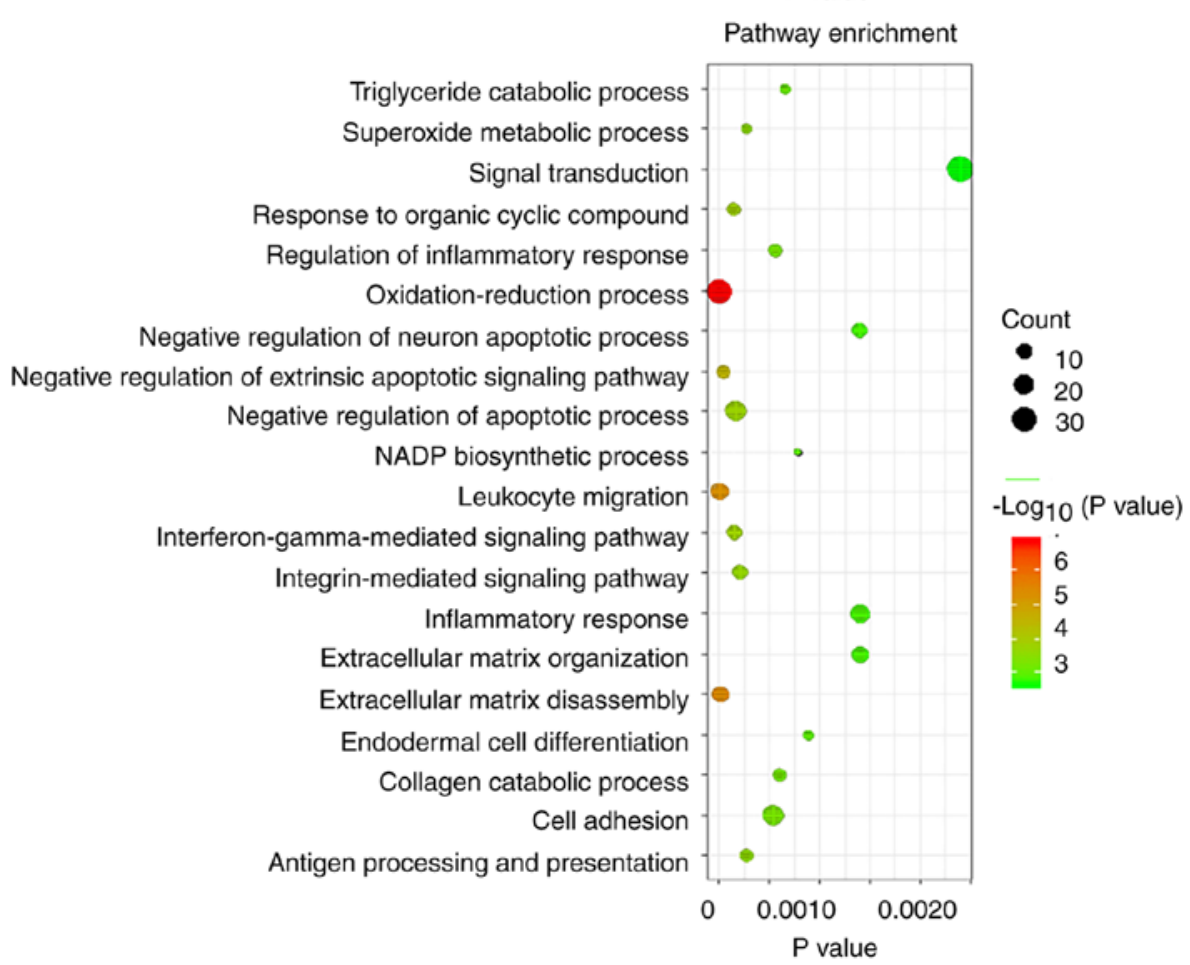

Figure 2. Differentially expressed genes and proteins. Bubble charts show enrichment of the differentially expressed genes/proteins in GO biological processes. (A) RNA-Seq result; (B) proteomic result (top 20 pathways). The abscissa represents the statistically significant level of enrichment analysis; the ordinate represents the description of the GO function. The count represents all differential genes/proteins associated with this term.

M0-DS macrophages expresses M2 markers, the protein and mRNA expression profiles of M0 and M2 macrophages were compared. Subsequently, the mRNA and protein abundances in M0 and M2 macrophages were analyzed by RNA sequencing and quantitative proteomics, respectively. The gene expression abundance was derived from the RNA-Seq data using the FPKM method. A total of 22,851 genes were detected and 458 genes were found to have significant differential expression. Among these genes, 291 were upregulated in M2 macrophages and 167 were downregulated (Fig. S2). A total of 5,455 proteins were identified using the shotgun proteomic method, with 4,940 proteins quantified by the LFQ algorithm (proteins with at least two unique peptides identified in all samples). Among the quantified proteins, 279 proteins (including 25 proteins expressed only in M2 macrophages) were upregulated in M2 macrophages and 407 were downregulated (including 138 expressed only in M0 macrophages) (Fig. S2). A total of 43 genes were upregulated in M2 


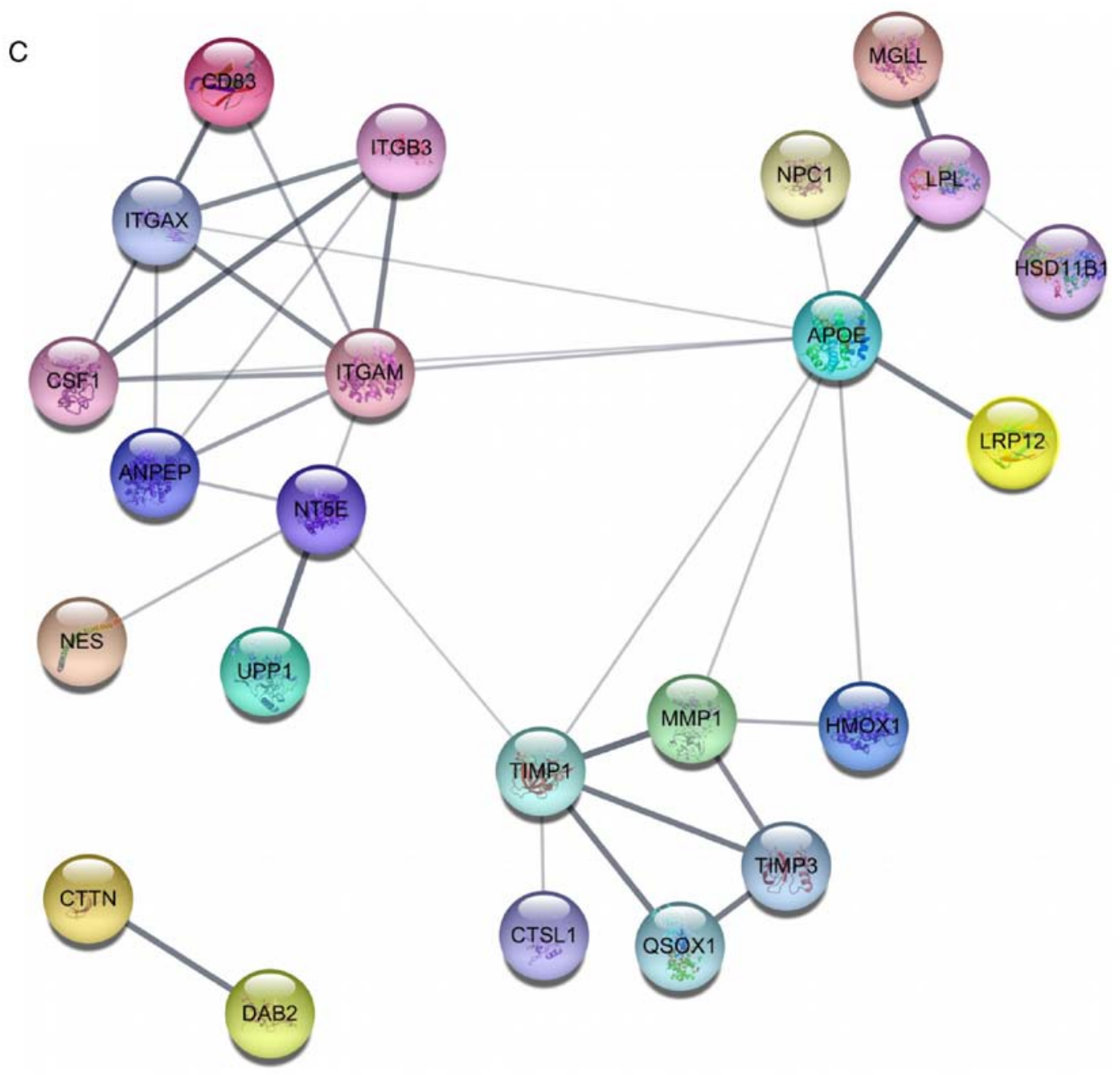

Figure 2. Continued. Differentially expressed genes and proteins. Bubble charts show enrichment of the differentially expressed genes/proteins in GO biological processes. (C) Protein interaction network analysis of the 43 upregulated proteins in Table II using the STRING website. GO, Gene Ontology.

macrophages at both the mRNA and protein levels, with an additional 13 gene downregulated at both levels (Table II). GO enrichment analysis was then performed on the differentially expressed genes. Genes involved in 'positive regulation of cell migration', 'collagen catabolic process', 'regulation of angiogenesis' and other functions that promote tumor metastasis were enriched in the upregulated mRNAs in M2 macrophages (Fig. 2A). At the protein level, those with higher abundance in the M2 macrophages were found to be involved in pathways including 'extracellular matrix disassembly', 'leukocyte migration', 'negative regulation of extrinsic apoptotic signaling pathway', 'cell adhesion' pathways (Fig. 2B). The following pathways were enriched at both the mRNA and protein levels: 'Inflammatory response', 'integrin-mediated signaling pathway', 'platelet degranulation', 'triglyceride catabolic process', 'viral entry into host cell' and 'extracellular matrix organization'. The STRING website was then used to perform a protein interaction network analysis of the 43 proteins that were upregulated at both the protein and mRNA levels. As shown in Fig. 2C, pathways involved in cell differentiation, matrix degradation and lipid transport were identified.

Apoptotic SKOV3-stimulated MO macrophages express M2 macrophage markers. To determine whether apoptotic
SKOV3-stimulated M0 macrophages differentiated into M2 macrophages and not M1 macrophages, markers for macrophage differentiation were examined $(7,23)$. For the controls, M0 macrophages were differentiated into M1 macrophages by incubation with LPS for $48 \mathrm{~h}$ (Fig. S3). M2 macrophages were generated by incubation of M0 macrophages with IL 4 for $48 \mathrm{~h}$ (23). The levels of the macrophage marker CD163, M1 marker CD68, and M2 markers CD204 and CD206 were then assessed by immunofluorescence. The apoptotic SKOV3-stimulated M0 macrophages had a low expression of the M1 marker CD68 but a high expression of the M2 marker CD206 (Fig. 3A). The mRNA expression levels of M2 markers C-C motif chemokine ligand 22 (CCL22) and IL-10 (25) were assessed by RT-qPCR analysis, and the levels were also high in the apoptotic SKOV3-stimulated M0 macrophages (Fig. 3B).

A number of the genes that were differentially expressed between M0 and M2 macrophages, including aminopeptidase-N (ANPEP), integrin $\alpha$-M (ITGAM), colony stimulating factor 1 (CSF1), disabled homolog 2 (DAB2), 5'-nucleotidase (NT5E) and matrix metalloproteinase (MMP)1 (Table II) were then selected for RT-qPCR analysis to assess mRNA levels. Each of these genes has previously been associated with the occurrence and development of tumors (26-31). Of these six 
A
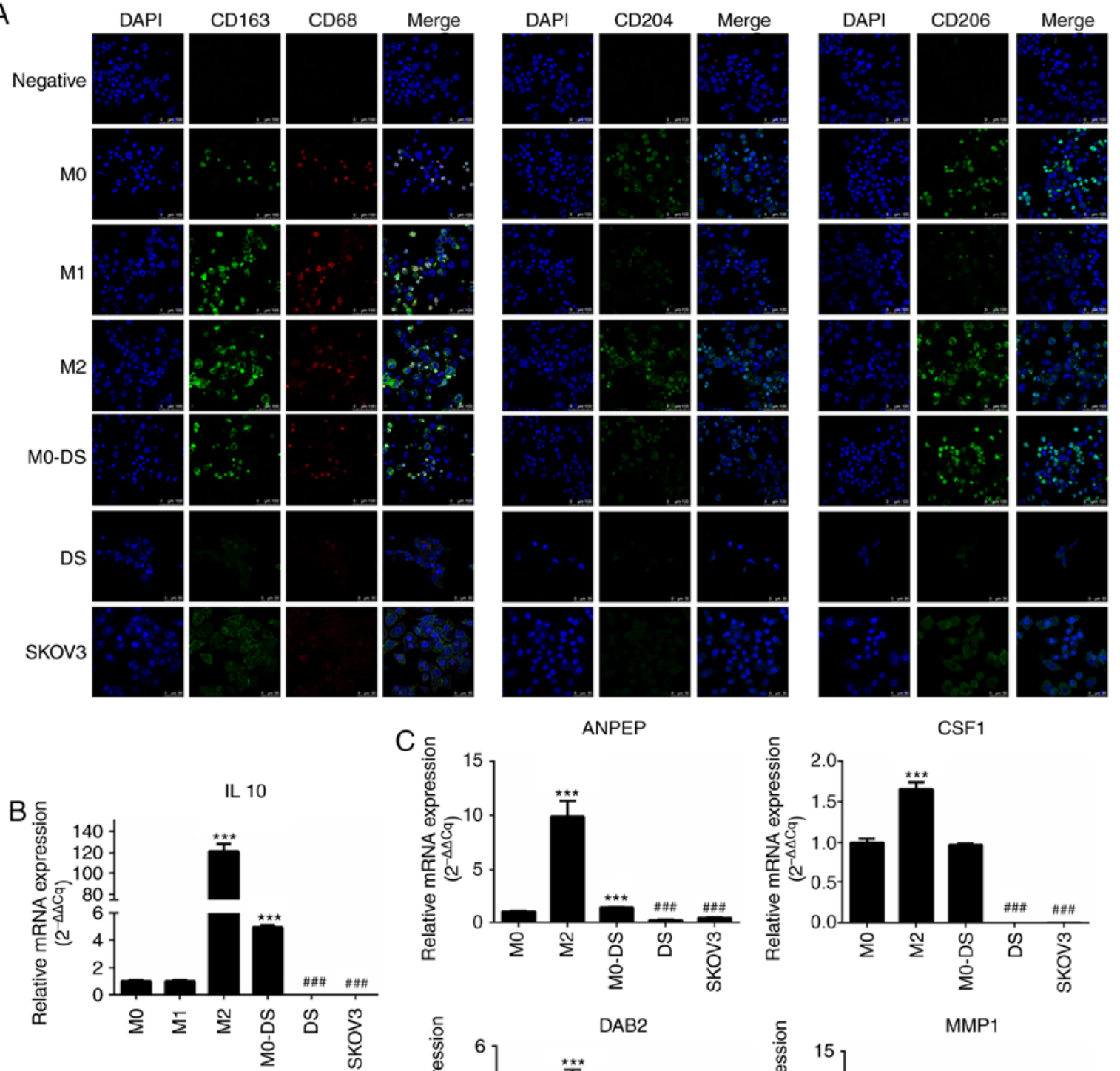

ANPEP
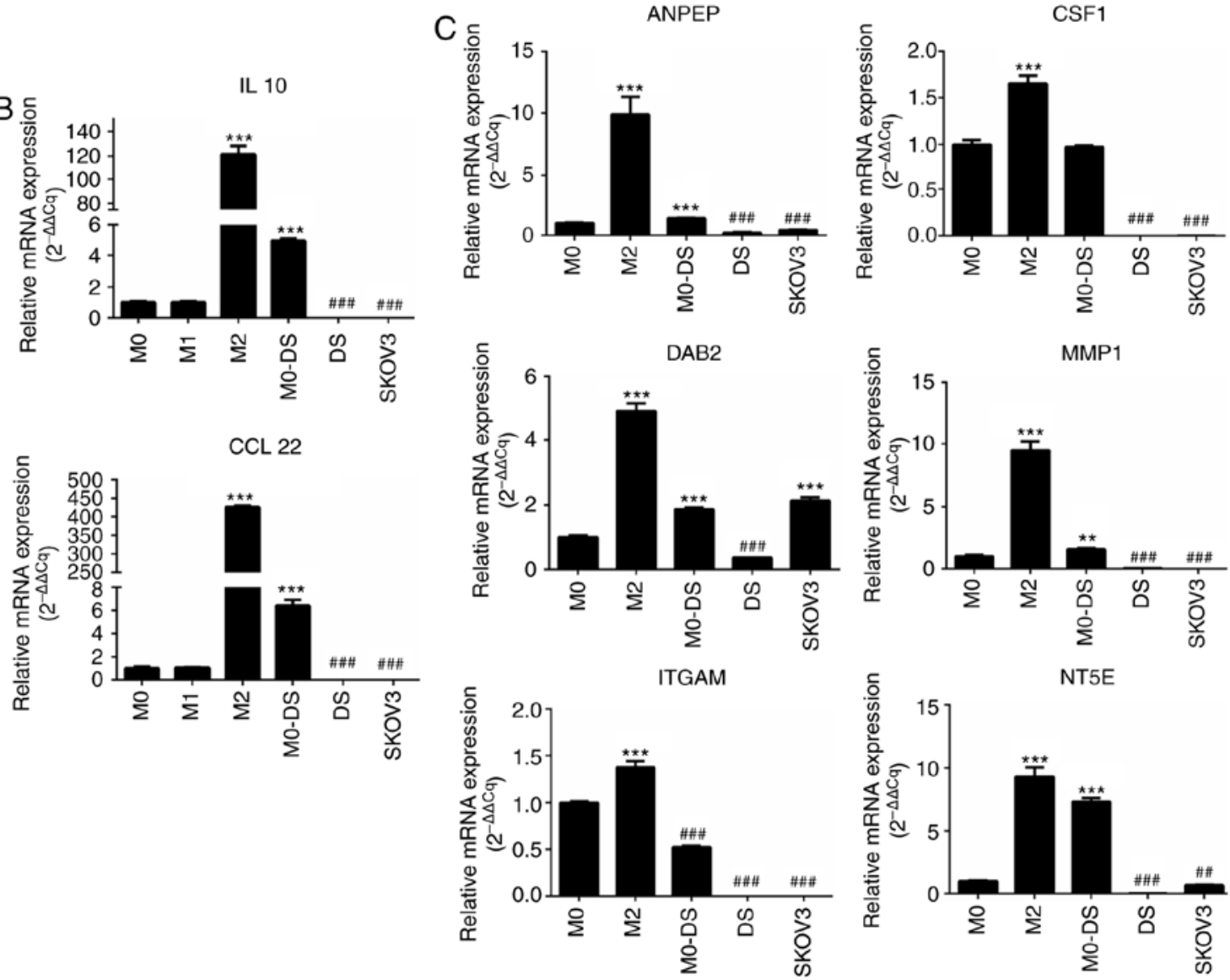

Figure 3. Differentiation of M0 macrophages into M2 macrophages. (A) Immunofluorescence of macrophage makers CD163, CD68, CD204 and CD206 in M0, M1 and M2 macrophages, apoptotic SKOV3-stimulated M0 macrophages, apoptotic SKOV3 cells and SKOV3 cells. M0, M1, M2, M0-DS group Scale bar, $100 \mu \mathrm{m}$; SKOV3, DS group Scale bar, $50 \mu \mathrm{m}$. (B) Relative mRNA expression levels of CCL22 and IL-10 in M0, M1 and M2 macrophages, apoptotic SKOV3-stimulated M0 macrophages, apoptotic SKOV3 cells and SKOV3 cells determined by RT-qPCR analysis. GAPDH was used as an internal standard. (C) Relative mRNA expression levels of ANPEP, CSF1, DAB2, MMP1, ITGAM and NT5E in M0 and M2 macrophages, apoptotic SKOV3-stimulated M0 macrophages, apoptotic SKOV3 cells, and SKOV3 cells determined by RT-qPCR analysis. GAPDH was used as an internal standard. Results are typical of three independent experiments. Data are presented as the mean $\pm \mathrm{SD}(\mathrm{n}=3)$. Intergroup differences were analyzed using one-way ANOVA. Tukey's post hoc test was used for the multiple comparisons among the various groups. ${ }^{* *} \mathrm{P}<0.01$ and ${ }^{* * *} \mathrm{P}<0.001$ vs. M0 macrophages; ${ }^{\# \#} \mathrm{P}<0.01$ and ${ }^{\# \# t} \mathrm{P}<0.001$ vs. M0 macrophages RT-qPCR, reverse transcription-quantitative PCR; DS, apoptotic SKOV3 cells; CCL22, IL, interleukin; ANPEP, aminopeptidase-N; CSF1, colony stimulating factor 1; DAB2, disabled homolog 2; ITGAM, integrin $\alpha$-M; MMP1, matrix metalloproteinase 1; NT5E, 5'-nucleotidase. 

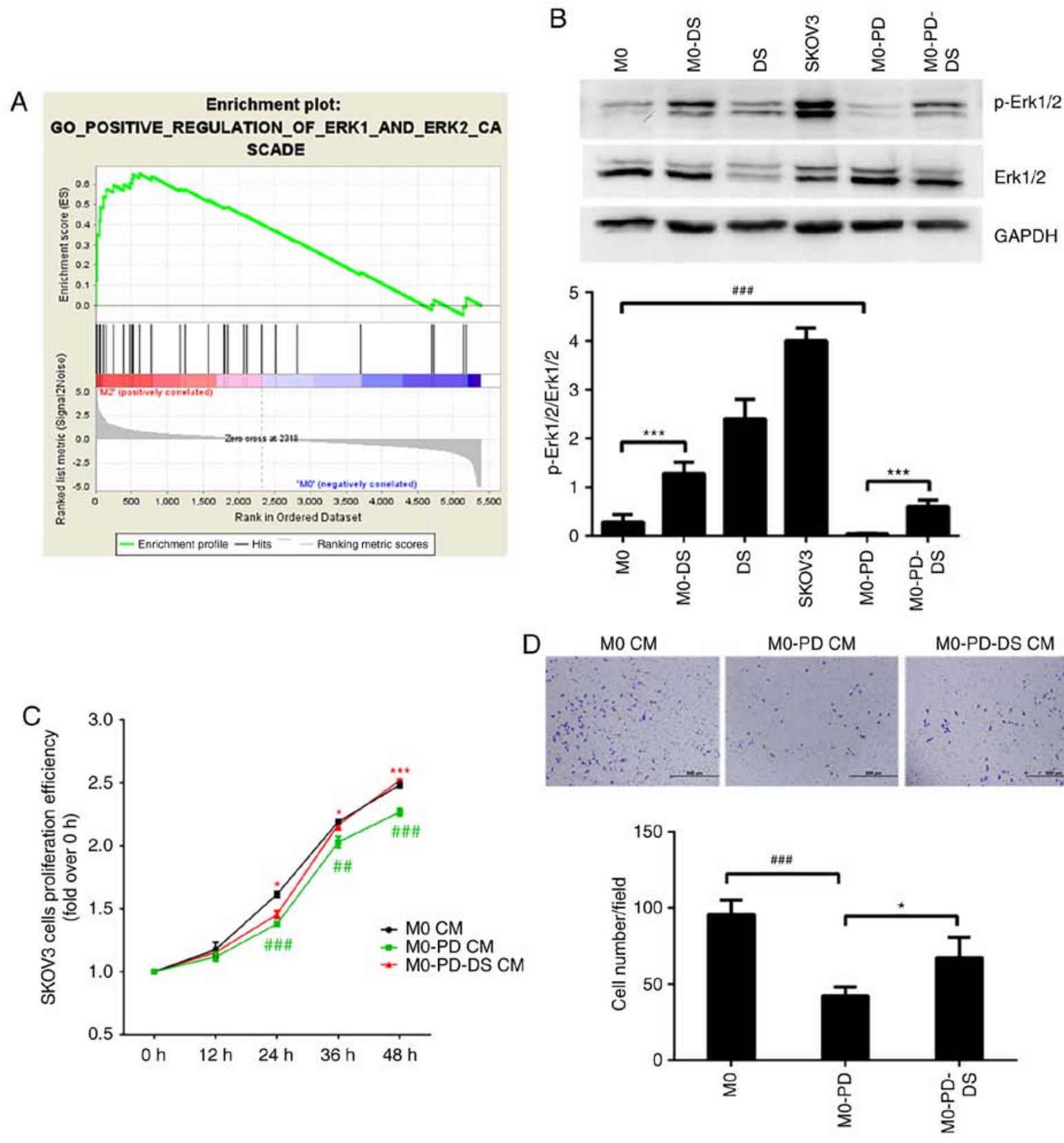

Figure 4. Role of ERK in M0 to M2 macrophage differentiation. (A) Gene Set Enrichment Analysis of the proteomic results from M0 and M2 macrophages. (B) Analysis of the phosphorylation of Erk1/2 in M0, M0-DS, apoptotic SKOV3, SKOV3, M0-PD and M0-PD-DS groups. ${ }^{* * *} \mathrm{P}<0.001 ;{ }^{* \# \#} \mathrm{P}<0.001$. (C) Cell counting kit-8 assay examining the proliferative ability of SKOV3 cells cultured with M0 CM, M0-PD CM, M0-PD-DS CM. "P<0.05 vs. M0-PD CM; ${ }^{* * *} \mathrm{P}<0.001$ vs. M0-PD CM group; ${ }^{\# /} \mathrm{P}<0.01$ vs. M0 CM group; ${ }^{\# \# \#} \mathrm{P}<0.001$ vs. M0 CM group (D) Transwell assay examining the migration ability of SKOV3 cells cultured with M0 CM, M0-PD CM and M0-PD-DS CM. "P<0.05 and ${ }^{\# \# / ~} \mathrm{P}<0.001$. Results are typical of three independent experiments. Data are presented as the mean $\pm \mathrm{SD}(\mathrm{n}=3)$. Intergroup differences were analyzed using one-way ANOVA. Tukey's post hoc test was used for the multiple comparisons among the various groups. CM, conditioned media; PD, PD98059; DS, apoptotic SKOV3 cells; p, phosphorylated.

genes, the expression levels of ANPEP, DAB2, MMP1 and NT5E were high in the M0-DS macrophage group (Fig. 3C). These results suggested that the apoptotic SKOV3-stimulated M0 macrophages had differentiated to become more similar to M2 macrophages.

Activation of the ERK signaling pathway in apoptotic SKOV3 stimulates the differentiation of MO macrophages into M2 macrophages and promotes the proliferation and migration of SKOV3 cells. GSEA software was used to analyze the proteins detected by LC-MS/MS, where it was found that proteins from M2 macrophages were enriched in the 'Positive regulation of Erk1/2 cascade' (Fig. 4A). This observation suggested that apoptotic SKOV3 cells may alter the ERK signaling pathway in M0 macrophages. The abundance of phosphorylated Erk1/2 proteins in M0 macrophages and M0-DS cells was examined by western blotting. To exclude the possibility of residual apoptotic SKOV3 cells accounting for the differences, the expression of Erk1/2 in apoptotic SKOV 3 cells was also examined. The results indicated that the abundance of phosphorylated Erk $1 / 2$ was increased in apoptotic SKOV3-stimulated MO macrophages (Fig. 4B). PD98059 is an inhibitor of Erk1/2 phosphorylation (32). M0-PD cells were generated when $5 \mu \mathrm{M}$ of PD98059 was 


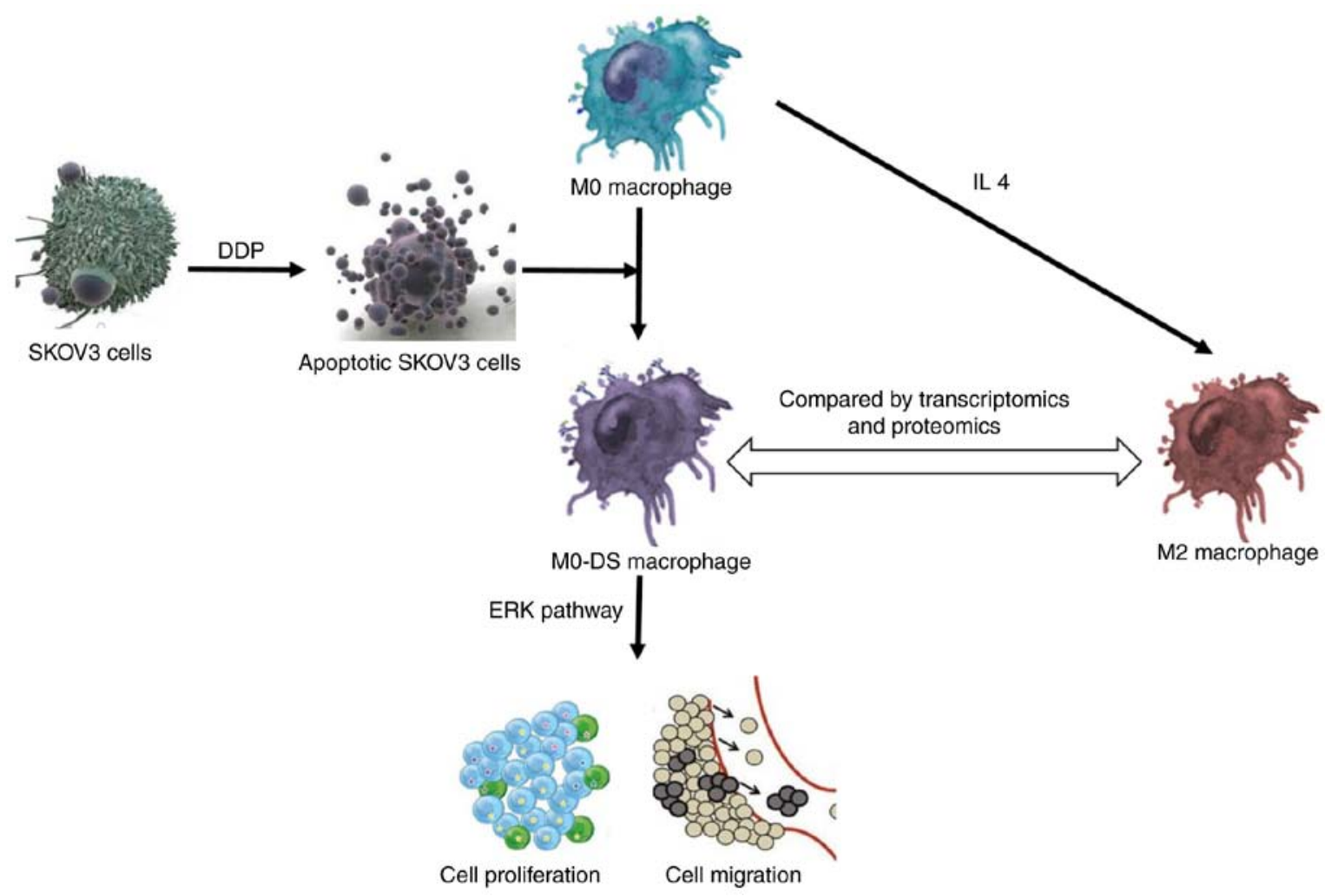

Figure 5. Schematic of cell interactions and differentiation. Apoptosis was induced in SKOV3 cells using DDP. Following stimulation by apoptotic SKOV3 cells, M0 macrophages (M0-DS macrophages) express M2 macrophage markers, and promote the proliferation and migration of SKOV3 cells by activating the ERK pathway. DPP, cisplatin; IL, interleukin.

added to the M0 macrophages for $48 \mathrm{~h}$. These M0-PD cells were then co-cultured with apoptotic SKOV3 cells at a ratio of $1: 1$ for $8 \mathrm{~h}$ to generate M0-PD-DS cells. The results showed that PD98059 significantly inhibited the phosphorylation of Erk1/2, but that the effect of PD98059 was inhibited following stimulation of the macrophages by apoptotic SKOV3 cells (Fig. 4B). Subsequently, to examine whether the ERK pathway serves a role in the proliferative and migratory abilities of SKOV3 cells, the cell proliferation and migration experiments were repeated in the M0-PD CM and M0-PD-DS $\mathrm{CM}$ cell groups. The proliferative and migratory abilities of the SKOV3 cells grown in M0-PD CM were significantly reduced, whereas the proliferative and migratory abilities of the SKOV3 cells grown in M0-PD-DS CM were partially restored (Fig. 4C and D). These results suggested that apoptotic SKOV3 cells stimulate M0 macrophages which serve a role in promoting SKOV3 cell proliferation and migration by activating the ERK signaling pathway.

\section{Discussion}

TAMs constitute an important part of the tumor-infiltrating immune cells and are involved in the growth, angiogenesis and metastasis of various types of cancer (33). The majority of TAMs are of the M2 macrophage phenotype (7). In the present study, experiments to examine mRNA and protein levels in M0 and M2 macrophages were performed by RNA-seq and quantitative proteomic techniques, respectively. Bioinformatic analysis of the resulting data indicated that M2 macrophages are enriched in mRNAs and proteins involved in numerous pathways, such as integrin-mediated signaling, extracellular matrix disassembly and PPAR signaling pathways. These pathways are closely associated with the occurrence and development of tumors $(31,34,35)$. In addition, new genes encoding proteins were identified, such as ANPEP, DAB2, MMP1 and NT5E, which may also be involved in the differentiation or function of these two types of macrophages. The function of these proteins and their roles in tumorigenesis remain to be fully elucidated, but they may be novel targets for tumor therapy.

In the present study, apoptotic SKOV3 cells were used to stimulate M0 macrophages and it was found that CM from these cells promoted the proliferation and migration of SKOV3 cells (Fig. 5). The apoptotic SKOV3-stimulated M0 macrophages exhibited downregulated expression of the M1 macrophage marker CD68 but upregulated expression of the M2 macrophage marker CD206, and increased mRNA levels of IL-10 and CCL22. These observations suggested that the M0 macrophages stimulated by apoptotic SKOV3 cells were transformed into M2-like macrophages. However, whether the M0 macrophages stimulated by apoptotic SKOV3 truly differentiated into M2 macrophages requires further investigation, as the gene expression patterns of the M0-DS and IL-4-induced M2 macrophages are not completely identical. The mRNA expression levels of CCL22 and IL-10 in M0 macrophages stimulated by apoptotic SKOV3 cells were significantly lower than those in M2 macrophages, and no significant increases in the mRNA expression levels of CSF1 and ITGAM were observed. This may be due to the fact that the pathways involved in apoptotic SKOV3-induced stimulation macrophage differentiation are 
not the same as those in IL-4 stimulation. Studies have shown that the differentiation of M0 macrophages is due to factors including CCL2 and VEGF, and is activated by the JAK/STAT and PI3K/AKT signaling pathways (36). The differentiation of M0 macrophages stimulated by apoptotic SKOV3 cells observed here may be due to these same pathways. Therefore, these may represent another type of TAM, or cells that are incompletely differentiated into M2 macrophages.

The ERK pathway is crucial for several biological processes and is important in the occurrence and development of cancer, including cell proliferation, differentiation, apoptosis, migration and invasion (37). The ERK pathway is also involved in the differentiation of M2 macrophages (38). The results of the present study indicated that apoptotic SKOV3 cells stimulate the phosphorylation of Erk1/2 in M0 macrophages. An inhibitor of Erk1/2 (PD98059) inhibited the proliferation and migration of SKOV3 cells, whereas apoptotic SKOV3 cells inhibited the function of PD98059, although not fully reversing its the effect, on the proliferation and migration of SKOV3 cells. This suggests that the effect of the apoptotic SKOV3 on M0 macrophages does not affect only the ERK pathway, but involves other pathways. Studies have shown that TAMs can degrade the basement membrane and extracellular matrix by using proteolytic enzymes, cathepsins and MMPs (39). The present study also revealed that the M2 macrophages exhibited high expression levels of genes and proteins in the extracellular matrix degradation pathway through bioinformatics analysis. This suggested that M0 macrophages stimulated by apoptotic SKOV3 cells also promote the migration of tumor cells through the extracellular matrix degradation pathway. To further examine that changes that occur in M0-DS cells, additional proteomic and RNA-Seq analyses are required.

Ovarian cancer is the most frequent cause of gynecologic malignancy-associated mortality. Although patients with ovarian cancer usually respond well to first-line chemotherapy based on platinum compounds and taxanes, the majority of these patients develop recurrence and chemotherapy-resistance $(2,24)$. The results of the present study suggest that the high recurrence may be due to apoptotic tumor cells stimulating M0 macrophages to differentiate into M2 macrophages. If true, this indicates possible treatments for patients with ovarian cancer who undergo chemotherapy; inhibiting M2 macrophage differentiation during chemotherapy may reduce the rate of tumor recurrence.

\section{Acknowledgements}

Not applicable.

\section{Funding}

The present study was supported by grants from the National Natural Science Foundation of China (grant. nos. 81673459 and 81874321), the National Key Technologies R\&D Program (grant. nos. 2012BAK25B01 and 2015BAK45B01) and a grant from the National Science Foundation of China-Canadian Institutes of Health Research (NSFC-CIHR) China-Canada Joint Health Research Initiative (grant. nos. 81061120525 and CCI-109605).

\section{Availability of data and materials}

The datasets used and/or analyzed during the present study are available from the corresponding author upon reasonable request.

\section{Authors' contributions}

QZ, HRT, GN and HYG designed the study. QZ, HL, YQM, XW, XHZ, XYY, JRT, ZL, CL, QH, LPS and YG performed the experiments and data analyses. QZ and DI contributed to drafting of the manuscript. All authors have read and approved the manuscript and agree to be accountable for all aspects of the research in ensuring that the accuracy and integrity of any part of the work are appropriately investigated and resolved.

\section{Ethics approval and consent to participate}

Not applicable.

\section{Patient consent for publication}

Not applicable.

\section{Competing interests}

The authors declare that they have no competing interests.

\section{References}

1. Siegel RL, Miller KD and Jemal A: Cancer statistics, 2017. CA Cancer J Clin 67: 7-30, 2017.

2. Kujawa KA and Lisowska KM: Ovarian cancer-from biology to clinic. Postepy Hig Med Dosw (Online) 69: 1275-1290, 2015 (In Polish).

3. Ju X, Yu H, Liang D, Jiang T, Liu Y, Chen L, Dong Q and Liu X: LDR reverses DDP resistance in ovarian cancer cells by affecting ERCC-1, Bcl-2, Survivin and Caspase-3 expressions. Biomed Pharmacother 102: 549-554, 2018.

4. Liu J and Matulonis UA: New strategies in ovarian cancer: Translating the molecular complexity of ovarian cancer into treatment advances. Clin Cancer Res 20: 5150-5156, 2014.

5. Hirata $\mathrm{E}$ and Sahai E: Tumor microenvironment and differential responses to therapy. Cold Spring Harb Perspect Med 7: a026781, 2017.

6. Quail DF and Joyce JA: Microenvironmental regulation of tumor progression and metastasis. Nat Med 19: 1423-1437, 2013.

7. Aras S and Zaidi MR: TAMeless traitors: Macrophages in cancer progression and metastasis. Br J Cancer 117: 1583-1591, 2017.

8. Orihuela R, McPherson CA and Harry GJ: Microglial M1/M2 polarization and metabolic states. Br J Pharmacol 173: 649-665, 2016.

9. Vinogradov S, Warren G and Wei X: Macrophages associated with tumors as potential targets and therapeutic intermediates. Nanomedicine (Lond) 9: 695-707, 2014.

10. Atri C, Guerfali FZ and Laouini D: Role of human macrophage polarization in inflammation during infectious diseases. Int J Mol Sci 19: E1801, 2018.

11. Van Ginderachter JA, Movahedi K, Hassanzadeh Ghassabeh G, Meerschaut S, Beschin A, Raes G and De Baetselier P: Classical and alternative activation of mononuclear phagocytes: Picking the best of both worlds for tumor promotion. Immunobiology 211 : 487-501, 2006.

12. Bingle L, Brown NJ and Lewis CE: The role of tumour-associated macrophages in tumour progression: Implications for new anticancer therapies. J Pathol 196: 254-265, 2002.

13. Lewis CE and Pollard JW: Distinct role of macrophages in different tumor microenvironments. Cancer Res 66: 605-612, 2006.

14. Pollard JW: Tumour-educated macrophages promote tumour progression and metastasis. Nat Rev Cancer 4: 71-78, 2004. 
15. Feng R, Morine Y, Ikemoto T, Imura S, Iwahashi S, Saito Y and Shimada M: Nrf2 activation drive macrophages polarization and cancer cell epithelial-mesenchymal transition during interaction. Cell Commun Signal 16: 54, 2018.

16. Wang Z, Gerstein M and Snyder M: RNA-Seq: A revolutionary tool for transcriptomics. Nat Rev Genet 10: 57-63, 2009.

17. Lehtonen A, Ahlfors H, Veckman V, Miettinen M, Lahesmaa R and Julkunen I: Gene expression profiling during differentiation of human monocytes to macrophages or dendritic cells. J Leukoc Biol 82: 710-720, 2007.

18. Li X, Wang W and Chen J: Recent progress in mass spectrometry proteomics for biomedical research. Sci China Life Sci 60: $1093-1113,2017$.

19. Kaltashov IA, Pawlowski JW, Yang W, Muneeruddin K, Yao H, Bobst CE and Lipatnikov AN: LC/MS at the whole protein level: Studies of biomolecular structure and interactions using native LC/MS and cross-path reactive chromatography (XP-RC) MS. Methods 144: 14-26, 2018.

20. Zhong L, Zhou J, Chen X, Lou Y, Liu D, Zou X, Yang B, Yin Y and Pan Y: Quantitative proteomics study of the neuroprotective effects of B12 on hydrogen peroxide-induced apoptosis in SH-SY5Y cells. Sci Rep 6: 22635, 2016.

21. Livak KJ and Schmittgen TD: Analysis of relative gene expression data using real-time quantitative PCR and the 2(-Delta Delta C(T)) method. Methods 25: 402-408, 2001.

22. Zeng C, Wang W, Yu X, Yang L, Chen S and Li Y: Pathways related to PMA-differentiated THP1 human monocytic leukemia cells revealed by RNA-Seq. Sci China Life Sci 58: 1282-1287, 2015.

23. Genin M, Clement F, Fattaccioli A, Raes M and Michiels C: M1 and M2 macrophages derived from THP-1 cells differentially modulate the response of cancer cells to etoposide. BMC Cancer 15: 577, 2015

24. Tan Y, Feng Q, Sun X, Xue M, Jiang N and Deng X: Effects of methylseleninic acid on cisplatin-resistant ovarian cancer cells (SKOV3/DDP) and the mechanisms. Zhong Nan Da Xue Xue Bao Yi Xue Ban 41: 1305-1311, 2016 (In Chinese; Abstract available in Chinese from the publisher).

25. Zheng P, Luo Q, Wang W, Li J, Wang T, Wang P, Chen L, Zhang P, Chen H, Liu Y, et al: Tumor-associated macrophagesderived exosomes promote the migration of gastric cancer cells by transfer of functional Apolipoprotein E. Cell Death Dis 9: $434,2018$.

26. Azimi A, Tuominen R, Costa Svedman F, Caramuta S, Pernemalm M, Frostvik Stolt M, Kanter L, Kharaziha P, Lehtiö J, Hertzman Johansson C, et al: Silencing FLI or targeting CD13/ANPEP lead to dephosphorylation of EPHA2, a mediator of BRAF inhibitor resistance, and induce growth arrest or apoptosis in melanoma cells. Cell Death Dis 8: e3029, 2017.

27. Salhia B, Kiefer J, Ross JT, Metapally R, Martinez RA, Johnson KN, DiPerna DM, Paquette KM, Jung S, Nasser S, et al: Integrated genomic and epigenomic analysis of breast cancer brain metastasis. PLoS One 9: e85448, 2014.
28. De I, Steffen MD, Clark PA, Patros CJ, Sokn E, Bishop SM, Litscher S, Maklakova VI, Kuo JS, Rodriguez FJ and Collier LS: CSF1 Overexpression promotes high-grade glioma formation without impacting the polarization status of glioma-associated microglia and macrophages. Cancer Res 76: 2552-2560, 2016.

29. Piao J, You K, Guo Y, Zhang Y, Li Z and Geng L: Substrate stiffness affects epithelial-mesenchymal transition of cervical cancer cells through miR-106b and its target protein DAB2. Int J Oncol 50: 2033-2042, 2017.

30. Zhu J, Zeng Y, Li W, Qin H, Lei Z, Shen D, Gu D, Huang JA and Liu Z: CD73/NT5E is a target of miR-30a-5p and plays an important role in the pathogenesis of non-small cell lung cancer. Mol Cancer 16: 34, 2017.

31. Yokoi A, Yoshioka Y, Yamamoto Y, Ishikawa M, Ikeda SI, Kato T, Kiyono T, Takeshita F, Kajiyama H, Kikkawa F and Ochiya T: Malignant extracellular vesicles carrying MMP1 mRNA facilitate peritoneal dissemination in ovarian cancer. Nat Commun 8: 14470, 2017.

32. Lin XL, He XL, Zeng JF, Zhang H, Zhao Y, Tan JK and Wang Z: FGF21 increases cholesterol efflux by upregulating ABCA1 through the ERK1/2-PPAR $\gamma$-LXR $\alpha$ pathway in THP1 macrophage-derived foam cells. DNA Cell Biol 33: 514-521, 2014.

33. Goswami KK, Ghosh T, Ghosh S, Sarkar M, Bose A and Baral R: Tumor promoting role of anti-tumor macrophages in tumor microenvironment. Cell Immunol 316: 1-10, 2017.

34. Niu J and Li Z: The roles of integrin $\alpha v \beta 6$ in cancer. Cancer Lett 403: 128-137, 2017.

35. Zhang T, Shao B and Liu GA: Rosuvastatin promotes the differentiation of peripheral blood monocytes into M2 macrophages in patients with atherosclerosis by activating PPAR- $\gamma$. Eur Rev Med Pharmacol Sci 21: 4464-4471, 2017.

36. Noy R and Pollard JW: Tumor-associated macrophages: From mechanisms to therapy. Immunity 41: 49-61, 2014.

37. Yu Z, Ye S, Hu G, Lv M, Tu Z, Zhou K and Li Q: The RAF-MEK-ERK pathway: Targeting ERK to overcome obstacles to effective cancer therapy. Future Med Chem 7: 269-289, 2015.

38. Kang H, Zhang J, Wang B, Liu M, Zhao J, Yang M and Li Y: Puerarin inhibits M2 polarization and metastasis of tumor-associated macrophages from NSCLC xenograft model via inactivating MEK/ERK 1/2 pathway. Int J Oncol 50: 545-554, 2017.

39. Chanmee T, Ontong P, Konno K and Itano N: Tumor-associated macrophages as major players in the tumor microenvironment. Cancers (Basel) 6: 1670-1690, 2014.

This work is licensed under a Creative Commons Attribution-NonCommercial-NoDerivatives 4.0 International (CC BY-NC-ND 4.0) License. 